\title{
Potential rice yields in future weather conditions in different parts of Asia
}

\author{
D. M. JANSEN*
}

Centre for Agrobiological Research, P.O. Box 14, NL 6700 AA Wageningen, Netherlands. Seconded to the International Rice Research Institute, P.O. Box 933, Manila, Philippines

Received 20 October 1989; accepted 6 June 1990

\begin{abstract}
Future climate change is expected to vary between regions, with possible different effects on crop growth. Various sites in Asia were selected to represent major rice growing environments. Historic weather data of these sites were adapted to possible changes in temperature and in $\mathrm{CO}_{2}$ level, to mimic climate change. Potential rice yields at present, and for the years 2020 and 2100 were calculated with a crop growth simulation model. Simulated yields rose in low and middle temperature change scenarios, but decreased in the high temperature scenario. Effects were stronger in the year 2100 , when also regional differences became clear: more than elsewhere, yields were affected by high temperatures between 10 and $35^{\circ} \mathrm{N}$. Water use efficiency decreased in the high temperature scenario irrespective of $\mathrm{CO}_{2}$ scenario, and increased otherwise.
\end{abstract}

Keywords: simulation, crop growth, climate change, carbon dioxide, temperature, radiation, Oryza sativa L., Asia

\section{Introduction}

The global climate appears to be changing with rising $\mathrm{CO}_{2}$ level and temperature (Trabalka et al., 1985; Jaeger, 1988). Already for some time, scientists and policy makers discuss the possible causes and solutions. Expectations for the change in $\mathrm{CO}_{2}$ level, as mentioned in literature, vary considerably, because of incertainties in the quantification of important sources and sinks in the global $\mathrm{CO}_{2}$ cycle. This makes it difficult to give an estimate for temperature change, eventhough it is generally accepted that a positive, and causal, relation exists between a change in $\mathrm{CO}_{2}$ concentration in the air, and a change in average global temperature.

In addition, there is considerable variation in the parameters used to quantify the relation between the two variables, among others because of the difficulty in evaluation of the effects on global temperature of other 'greenhouse' gasses (as methane,

Present address: Department of Theoretical Production Ecology, Wageningen Agricultural University, P.O. Box 430, NL 6700 AK Wageningen, Netherlands. 
ozone, nitrous-oxides). Huge General Circulation Models (GCM's) have been developed to calculate the effect on climate of changes in chemical composition of the atmosphere. Resulting from differences in assumptions or computation methods, they give various projections of climate change, even at the same rate of increase in $\mathrm{CO}_{2}$ level. All together, there are various possible changes in $\mathrm{CO}_{2}$ level, and for each of these there are again various possible temperature changes.

The scope of this paper is to investigate the effect of possible changes in these variables on rice production and on water use efficiency. For this purpose, it doesn't seem inappropriate to assume that changes in $\mathrm{CO}_{2}$ level and temperature are independent of each other, as long as the range of change for each variable is within the range mentioned in the literature.

There are indications that a change in global temperature will result in different regional and seasonal changes in temperature (Jaeger, 1988). Together with the current regional variation in weather, this might cause a regional effect on rice production of global change in $\mathrm{CO}_{2}$ level and temperature.

For policy makers, and for scientists involved in rice research, especially those oriented at breeding of new cultivars, it is interesting to know to what extent the rice crop is affected by the expected or possible climate change. As the climate change occurs in time, projections of the future weather at two points in time were made for each of the scenario's. One for the medium term at the year 2020, and the other at the year 2100. Calculated yields for present conditions were used as a reference.

At present, rice is grown in a wide range of climates, with average temperatures mostly between $20-30{ }^{\circ} \mathrm{C}$ (Oldeman et al., 1987). The optimum temperature for many physiological processes is $25-30{ }^{\circ} \mathrm{C}$ and the limiting temperature is $35-45{ }^{\circ} \mathrm{C}$ (Yoshida, 1981). This indicates that temperatures during the day can be harmful, and that even a small temperature rise could have negative effects on rice growth. The negative effect of temperature could (partially) be counteracted by a rise in $\mathrm{CO}_{2}$ level. Photosynthesis of rice increases curvilinearly with $\mathrm{CO}_{2}$ level, leading to faster growth (Akita, 1980; Imai et al., 1985; Saitoh \& Ishihara, 1987). This corresponds with findings in other $\mathrm{C}_{3}$ crops (Cooper, 1982; Goudriaan \& de Ruiter, 1983; Goudriaan \& Bijlsma, 1987; Jones et al., 1985). Simulations indicate that the direction of change in yields of soybean and maize in the southern USA depends on the specific combination of future temperature and $\mathrm{CO}_{2}$ level (Curry et al., 1988).

In many rainfed rice areas, water availability limits rice yield (Fukui, 1982). Higher temperatures in general increase transpiration rates and reduce water use efficiencies (in $\mathrm{kg}$ biomass produced per $\mathrm{kg}$ water transpired), thus leading to more drought stress. In contrast, a rise in ambient $\mathrm{CO}_{2}$ level often results in higher water use efficiencies, and therefore possibly to less drought stress. During the day, the $\mathrm{CO}_{2}$ concentration in the stomatal cavity of rice tends to be a constant fraction of that in the ambient air. The photosynthetic rate of rice increases curvilinearly with the $\mathrm{CO}_{2}$ concentration in the stomatal cavity (Dingkuhn, 1985; Fukai et al., 1985; Saitoh \& Ishihara, 1987), whereas stomatal resistance and transpiration rate seem to be independent of $\mathrm{CO}_{2}$ concentration (Akita, 1980; Dingkuhn, pers. comm.). 
This results in a curvilinear increase in water use efficiency when $\mathrm{CO}_{2}$ concentration rises, as shown by Akita (1980).

This study aims at providing estimates for changes in potential yield and water use efficiency in major rice growing areas. De Wit \& Penning de Vries (1982) defined potential production as the production limited by crop characteristics and current temperature and radiation, without any stress resulting from water or nutrient shortages.

In most regions actual production is below potential, even when ample water is available. This is often due to low nitrogen availability. Effects of increased $\mathrm{CO}_{2}$ vary with $\mathrm{N}$ level (Goudriaan $\&$ de Ruiter, 1983). An attempt is made to quantify also the effect of climate change on rice yield under low nitrogen availability.

Water use efficiency under water stress is similar to that in the same weather conditions but with ample water (de Wit, 1958; Tanner \& Sinclair, 1983). Therefore, the insight in effect of changes in $\mathrm{CO}_{2}$ and temperature on the water use efficiency in potential conditions can be extrapolated to situations with limited water availability.

\section{Materials and methods}

\section{Model}

The modular dynamic crop growth simulation model MACROS (Penning de Vries et al., 1989) combines effects of temperature, radiation, wind speed, air humidity, and crop status on physiological processes. Daily rates of photosynthesis, respiration, transpiration, and phenological development are calculated. The MACROS module used, integrates these rates with time steps of one day to calculate biomass and phenological stage.

Crop photosynthesis relates to leaf area via a procedure linking leaf photosynthesis to light intensity (Goudriaan, 1986), characterized by two parameters: the rate at light satuation (PLMX) and the light use efficiency at low light intensity (PLEA). The relation of PLMX to temperature follows an optimum curve. For most rice cultivars $30^{\circ} \mathrm{C}$ is optimal (Sato, 1970; McDonald, 1971; Vong \& Murata, 1977; Ishii et al., 1977; Akita, 1980), but differences exist between cultivars (Osada, 1964; Heu, 1978). The relative decline of photosynthesis at higher temperatures appears to be cultivar specific. However, most measurements on photosynthesis above $30^{\circ} \mathrm{C}$ were done on plants raised at lower temperatures. Higher pretreatment temperatures (up to $35^{\circ} \mathrm{C}$ ) lead to higher photosynthetic rates at $28-30^{\circ} \mathrm{C}$ (Sato, 1970). Data on effects on pretreatment at higher temperatures were not found. Data to relate PLEA to pretreatment temperature were even more scarce than those for PLMX. In this study therefore, relations of PLMX and PLEA to temperature were used as suggested by Penning de Vries et al. (1989; Figure 1A). A $\mathrm{CO}_{2}$ effect was added (Figure 1B). A doubling of the $\mathrm{CO}_{2}$ level in 1980 of $338 \mathrm{ppm}$ (Jaeger, 1988) yields a 1.5fold increase of PLMX in the model, in line with data on rice (Saitoh \& Ishihara, 1987), but less than for wheat (Goudriaan et al., 1985). Simulated PLEA rose $25 \%$ over the same $\mathrm{CO}_{2}$ range, similar to wheat (Goudriaan et al., 1984). Following van 


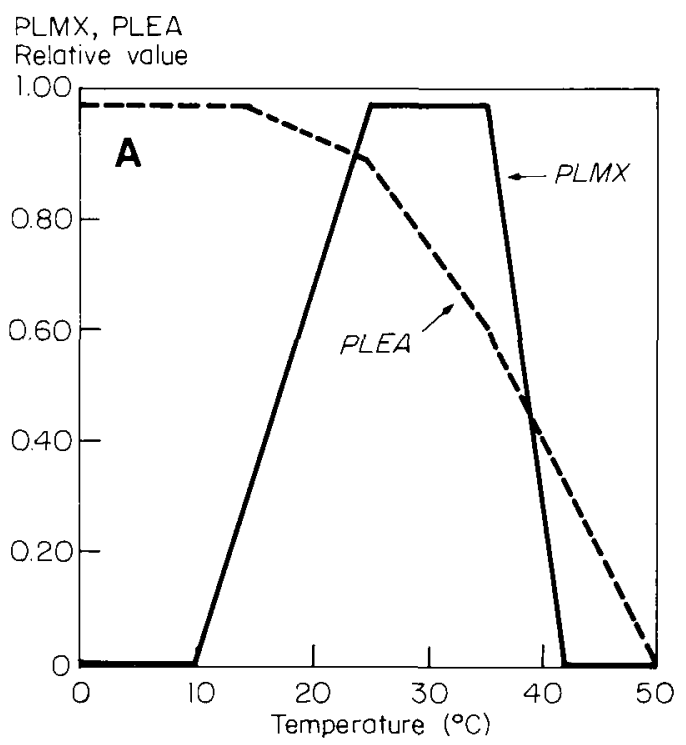

Fig. 1A. Effect of temperature on maximum photosynthetic rate (PLMX) and initial light use efficiency (PLEA). After Penning de Vries et al. (1989).

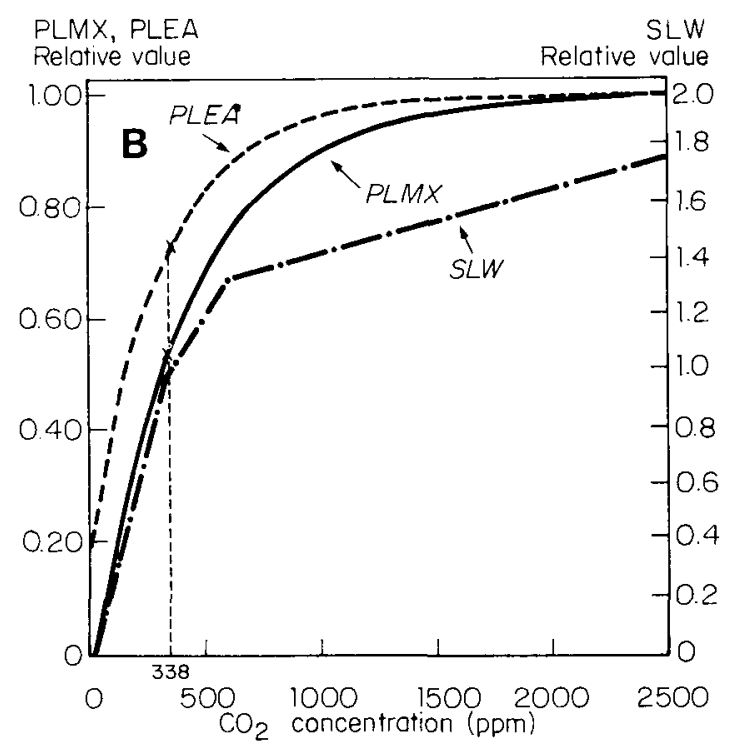

Fig. 1B. Effect of $\mathrm{CO}_{2}$ concentration on maximum photosynthetic rate (PLMX), initial light use efficiency (PLEA) and specific leaf weight (SLW). Temperature of measurements of photosynthesis parameters: $28-30^{\circ} \mathrm{C}$. PLEA curve below $250 \mathrm{ppm} \mathrm{CO} \mathrm{CO}_{2}$ is extrapolated. Based on Akita (1980), Cooper (1982), van Diepen et al. (1987). 
Diepen et al. (1987) also an effect of $\mathrm{CO}_{2}$ on the specific leaf weight was assumed (Figure 1B). This relation is almost linear up to $\mathrm{CO}_{2}$ levels expected in the year 2020, that range between 396 and $429 \mathrm{ppm}$. In the original model, PLMX increases linearly with specific leaf weight (till a maximum). Thus values of PLMX above 100 $\mathrm{kg} \mathrm{CO} \mathrm{ha}^{-1} \mathrm{hr}^{-1}$ were calculated, which seems incorrect for rice regarding the literature (Akita, 1980; Saitoh \& Ishihara, 1987; Ishii et al., 1977). In the current model therefore only the relation of specific leaf weight to $\mathrm{CO}_{2}$ was used.

A modified Penman equation was used to simulate potential transpiration, with intercepted radiation, air temperature and air humidity as driving factors (Penning de Vries et al., 1989). Stomatal, boundary layer and turbulence resistances (the latter two depending on wind speed and crop structure) co-determine the transpiration rate. Stomatal resistance is calculated from the average photosynthetic rate per unit leaf area and the gradient between ambient $\mathrm{CO}_{2}$ and $\mathrm{CO}_{2}$ in the stomatal cavity. The latter is linearly related to the ambient $\mathrm{CO}_{2}$ concentration.

Herrera-Reyes \& Penning de Vries (1990) showed a good agreement between the yields calculated by the MACROS model and yields obtained at Los Banos, Philippines, in actual weather conditions, under management conditions that were close to optimal. Grain yield of rice can be limited by the number of the grains, as the hull doesn't permit the grain to grow beyond a certain maximum size. The present model doesn't simulate this morphological limit to grain yield. Therefore simulations were terminated when a harvest index of 0.5 was reached, which seems to be an upper limit for current rice cultivars (e.g. Yoshida, 1983).

Crop data used were for the indica-type cultivar IR 36, at present one of the most widely grown cultivars, for which estimates of most of the required physiological parameters were available (Penning de Vries et al., 1989). IR 36 might differ from cultivars used in the areas concerned. Therefore, potential yields presented here might not be the real potentials for these areas. Especially when cultivars are used that have a different growing duration, the differences might be large. However, it is expected that the calculated trends are indicative for all cultivars.

To calculate the effect of continuous low $\mathrm{N}$ uptake rates, simulation runs were made assuming that the maximum photosynthetic rate of the leaf during the whole growing season is only one third of the potential rate.

\section{Locations}

The following five countries were selected for this simulation study: the People's Republic of China, India, Indonesia, Thailand and South Korea. P.R. China, India and Indonesia together produce about $65 \%$ of the world rice, which is almost completely consumed locally.

Relatively little import and export takes place: from 1981-1986 these countries accounted for $9 \%$ of the total world import and $12 \%$ of the export (IRRI, 1988). The major rice-exporter is Thailand, ranking 5 th in total production, but accounting for about $31 \%$ of the total world export. It is clear, that changes in rice production in these four countries can have a major impact on rice prices and on availability of rice to the rural and urban poor. In this study attention was also given to rice 
production in South Korea. Korea is rather far north for rice production (with possibly larger changes in temperature) and this region has the world's highest average rice production per ha (IRRI, 1988).

\section{Weather data}

In P.R. China, 10 of the 31 provinces account for $85 \%$ of the rice growing area (Huke, 1982). Weather data were only available for Hangzhou in Zhejiang province (with circa $7.5 \%$ of the total planted area in China). It is unknown to what extent these data represent the whole rice growing environment in China.

In India, rice is grown in various climatic conditions. Weather data used were from two different areas (Oldeman et al., 1987): Cuttack (Orissa) with low radiation and a seasonal variation in minimum temperature of $8-15^{\circ} \mathrm{C}$ (similar to the other major rice-growing states Bihar and West Bengal) and Coimbatore (Tamil Nadu) with high radiation and only $3-8{ }^{\circ} \mathrm{C}$ variation in minimum temperature. It is expected that the differences between these two sites are representative for the variability of India's rice growing areas.

Java accounts for about $63 \%$ of the rice production in Indonesia, to which West Java contributes about one third (Oldeman \& Frère, 1982). Muara and Pusakanegara were chosen to depict the environmental variability.

Khon Kaen in northeast Thailand was chosen, where production is often limited by water availability (especially in the dry season). Changes in water use efficiency of the crop could affect the area that can be brought under irrigation.

For Korea, weather data from Suweon were used, as an average between the relative warm southern regions and the colder mountainous areas.

To account for the variability between the seasons that exist in most locations, two planting dates were chosen, one in the major season, and the other in the offseason. Table 1 lists for each site the geographical data, the transplanting dates and the years for which weather data were available.

Table 1. Geographical data of the locations and the planting dates and years of weather data used.

\begin{tabular}{|c|c|c|c|c|c|c|}
\hline \multirow[t]{2}{*}{ Place } & \multirow{2}{*}{\multicolumn{2}{|c|}{ Latitude }} & \multirow[t]{2}{*}{ Elevation } & \multicolumn{2}{|c|}{ Planting datel } & \multirow[t]{2}{*}{ Years } \\
\hline & & & & main & off season & \\
\hline Hangzhou, P.R. China & $30^{\circ} 6{ }^{\prime}$ & $\mathrm{N}$ & $40 \mathrm{~m}$ & 145 & 215 & $\begin{array}{l}1974,1975,1977,1978, \\
1979,1982,1983,1984\end{array}$ \\
\hline Cuttack, India & $20^{\circ}$ & $\mathbf{N}$ & $23 \mathrm{~m}$ & 183 & 1 & $1984,1985,1987$ \\
\hline Coimbatore, India & $11^{\circ}$ & $\mathrm{N}$ & $427 \mathrm{~m}$ & 181 & 245 & $1984,1987,1988$ \\
\hline Muara, Indonesia & $6^{\circ} 36^{\prime}$ & $\mathrm{S}$ & $240 \mathrm{~m}$ & 46 & 196 & $1981-1985$ \\
\hline Pusakanegara, Indonesia & $6^{\circ} 20^{\prime}$ & $\mathrm{S}$ & $7 \mathrm{~m}$ & 46 & 196 & $1981-1984$ \\
\hline Khon Kaen, Thailand & $16^{\circ} 30^{\prime}$ & $\mathrm{N}$ & $195 \mathrm{~m}$ & 213 & 15 & $1985-1987$ \\
\hline Suweon, S. Korea & $37^{\circ} 20^{\prime}$ & $\mathrm{N}$ & $30 \mathrm{~m}$ & 145 & 165 & $1980-1987$ \\
\hline
\end{tabular}

1 Julian date. 
Future weather scenarios

Carbon dioxide. For this study, three scenarios were defined that encompass most ranges of expected $\mathrm{CO}_{2}$ increase (Clark et al., 1982; Trabalka et al., 1985; Figure 2). Especially the northern hemisphere shows a seasonality of the $\mathrm{CO}_{2}$ level in the air (Gammon et al., 1985). This is also taken into account (Figure 3A) since in some places the seasonal variation of the $\mathrm{CO}_{2}$ level $(>12 \mathrm{ppm})$ is substantial compared to the expected change in global average for the near future.

Temperature. Three temperature scenarios were used, with a rise in average global temperature of $0.06,0.3$ and $0.8^{\circ} \mathrm{C}$ per decade (Jaeger, 1988; Figure 2). Northern hemisphere winter temperatures are expected to increase relatively more than summer temperatures, of than year-round temperatures in regions close to or south of the equator (Jaeger, 1988). A relation between latitude and seasonal change in temperature was introduced (Figure 3B).

Radiation. Effects of three levels of radiation fluxes were calculated: measured fluxes, and (arbitrarily chosen) $110 \%$ and $90 \%$ of those values, assuming no change in wavelength composition.

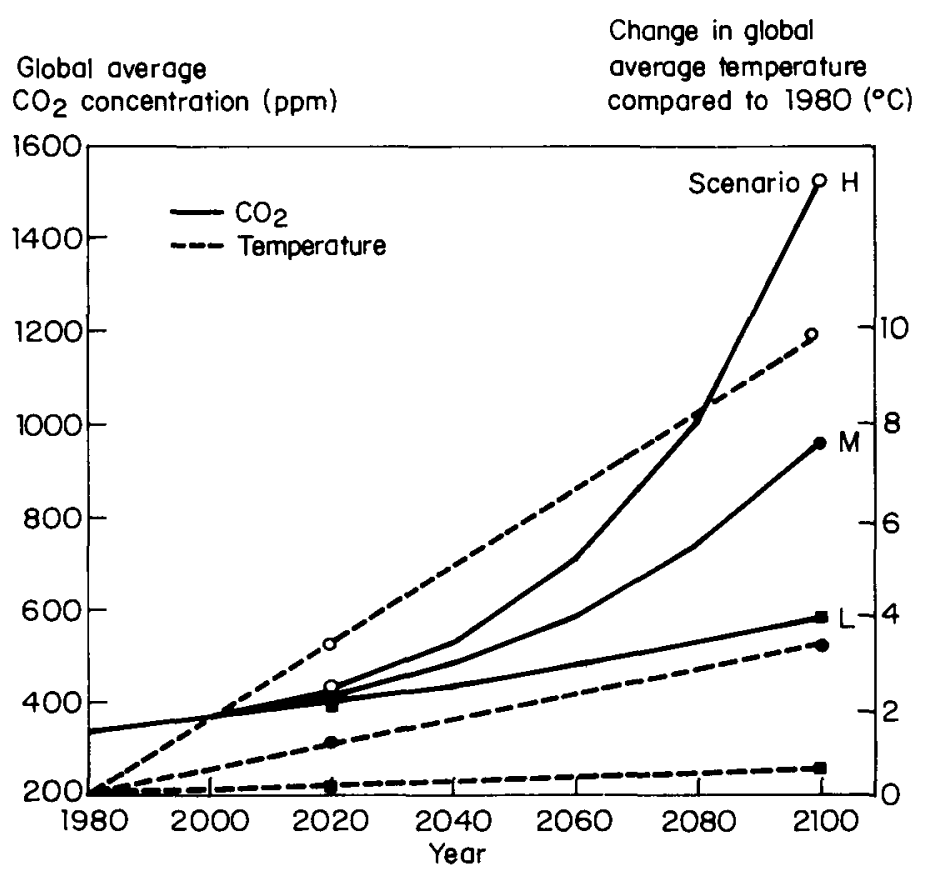

Fig. 2. Changes with time of the global average $\mathrm{CO}_{2}$ concentration in the air and of the global average temperature change for the scenarios used in this study. 


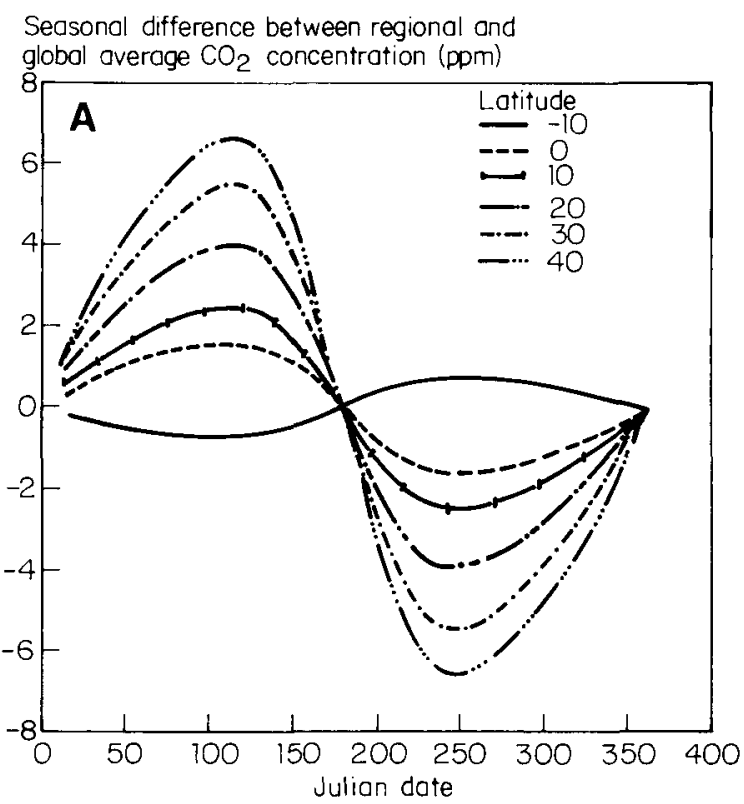

Fig. 3A. Assumed seasonal variation in $\mathrm{CO}_{2}$ concentration at various latitudes. $\mathrm{CO}_{2}$ concentration in ppm difference with annual global average. After Gammon et al. (1985).

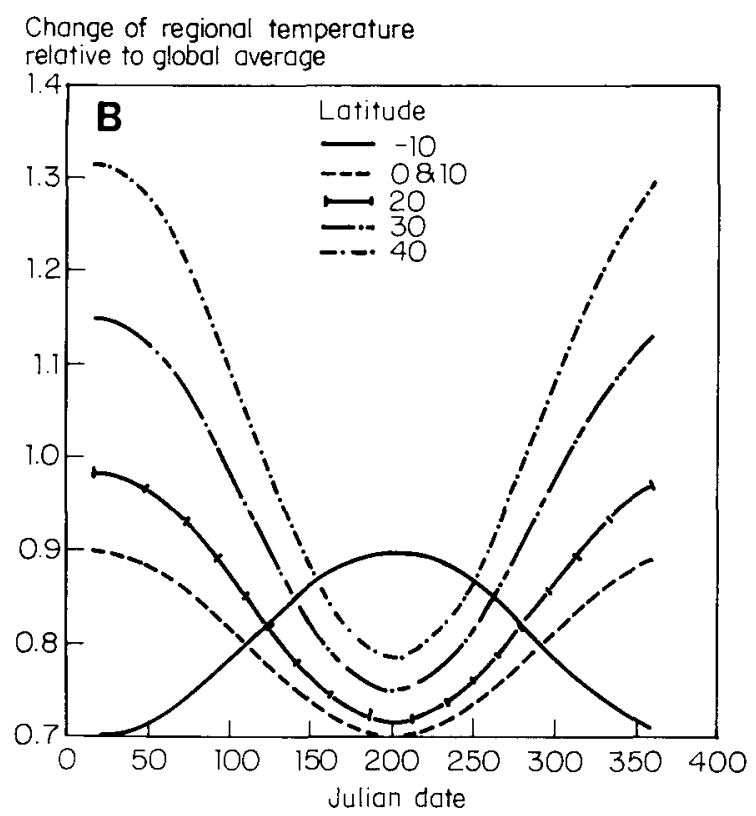

Fig. 3B. Assumed seasonal variation in temperatures as fraction of annual global average. After Jaeger (1988). 
Table 2. Combinations of temperature, $\mathrm{CO}_{2}$ and radiation scenarios used in the study.

\begin{tabular}{|c|c|c|c|c|}
\hline \multirow[t]{2}{*}{ Radiation } & \multirow[t]{2}{*}{$\mathrm{CO}_{2}$} & \multicolumn{3}{|c|}{ Temperature } \\
\hline & & Low & Medium & High \\
\hline \multirow[t]{3}{*}{$90 \%$ of actual } & Low & $\mathrm{LL}-10$ & $M L-10$ & $\mathrm{HL}-10$ \\
\hline & Medium & $\mathrm{LM}-10$ & $\mathrm{MM}-10$ & $\mathrm{HM}-10$ \\
\hline & High & $\mathrm{LH}-10$ & $\mathrm{MH}-10$ & $\mathrm{HH}-10$ \\
\hline \multirow{3}{*}{ Actual } & Low & LLO & MLO & HLO \\
\hline & Medium & LMO & MM0 & HMO \\
\hline & High & LHO & MHO & HHO \\
\hline \multirow[t]{3}{*}{$110 \%$ of actual } & Low & $\mathrm{LL}+10$ & $M L+10$ & $\mathrm{HL}+10$ \\
\hline & Medium & $\mathbf{L M}+10$ & $M M+10$ & $\mathrm{HM}+10$ \\
\hline & High & $\mathrm{LH}+10$ & $\mathrm{MH}+10$ & $\mathrm{HM}+10$ \\
\hline
\end{tabular}

Combinations. A total of 27 weather scenarios resulted (Table 2). Estimates of future weather were made by adding the calculated change in $\mathrm{CO}_{2}$ level and temperature to measured values (assuming a global level of $338 \mathrm{ppm} \mathrm{CO}$ in 1980). Thirty four years of data thus yielded 918 sets of weather estimates. Potential yield and water use efficiency at present and in the years 2020 and 2100 were simulated for two transplanting dates, amounting to 5508 runs. Nitrogen limited production was calculated for all the temperature and $\mathrm{CO}_{2}$ scenarios but at the measured radiation level only (1224 runs). For Khon Kaen the water use efficiency was calculated with the same vapour pressure in the air as at present, to compare with the water use efficiency at the same relative humidity as at present (486 runs). With in total 7218 runs, it will be clear that not all the output can be presented.

\section{Results}

\section{Potential yield under unchanged radiation}

Figures 4 and 5 show potential yield for the years 2020 and 2100 versus that at present. Changes in temperature appeared much more important than changes in $\mathrm{CO}_{2}$ level. For the year 2020, the highest and lowest $\mathrm{CO}_{2}$ level differed ca. $33 \mathrm{ppm}$, and differences in calculated yields between the extreme $\mathrm{CO}_{2}$ levels were circa $4 \%$ at any temperature scenario. This is much less than the circa $24 \%$ difference in calculated yields between lowest and highest temperature scenario at any $\mathrm{CO}_{2}$ scenario (Table 3). For the year 2100 the difference in $\mathrm{CO}_{2}$ level between the highest and lowest $\mathrm{CO}_{2}$ scenarios was $944 \mathrm{ppm}$. Effect of $\mathrm{CO}_{2}$ scenario was therefore larger for the year 2100 than for the year 2020: differences in calculated yields between highest and lowest $\mathrm{CO}_{2}$ scenario were 25,22 and $13 \%$ for low, middle and high temperature scenario respectively.

For the low temperature-change scenario, potential yield rose 6-19\% for the year 2020 (Table 3), while its coefficient of variation remained almost the same as at 


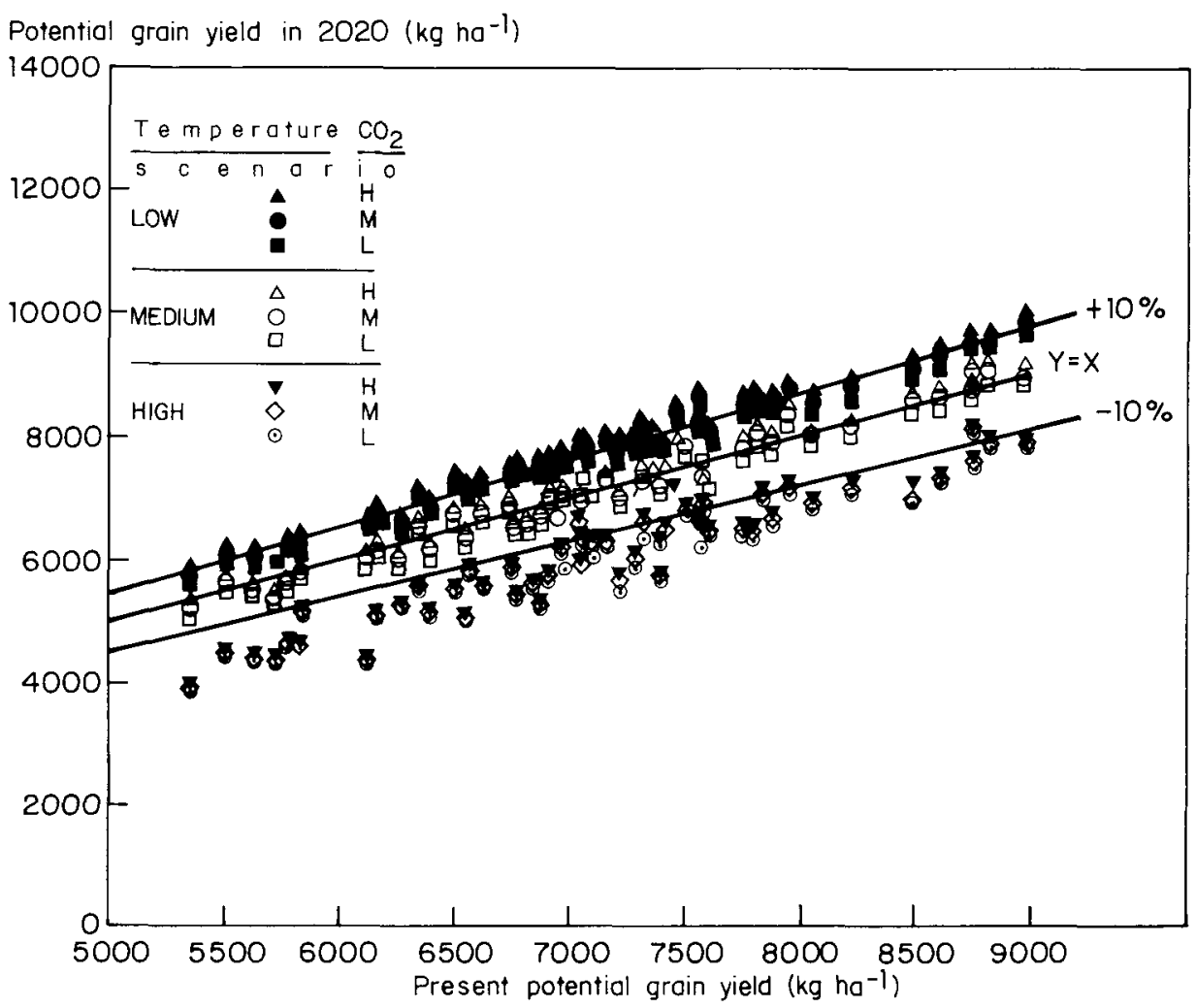

Fig. 4. Potential rice grain yields in the year 2020 versus present potential yields.

present (Table 4). The medium temperature-change scenario resulted in the same potential yields for the year 2020 as at present, but showed an increase in the coefficient of variation of $30 \%$ for the main season and of $15 \%$ for the off season. A $15 \%$ decrease in potential yield was calculated for the high temperature scenario, whereas the coefficient of variation became larger with an increase of $100 \%$ in the main and of $20 \%$ in the off season. Potential production of rice in general decreased and became more variable with increasing temperatures.

These trends for potential yield in the year 2020 were found for all sites (Figure 6) and for both transplanting dates. There was some scatter in the changes in coefficient of variation $(\mathrm{CV})$, which is partly due to the limited number of years of weather data. This was especially true for Coimbatore, where for present conditions a CV of less than $0.5 \%$ was calculated, and a small absolute change in CV resulted in a large relative change.

In the year 2100 , the differences in yield between the temperature scenarios became larger. The potential production rose in the low scenario with $20-45 \%$ de- 


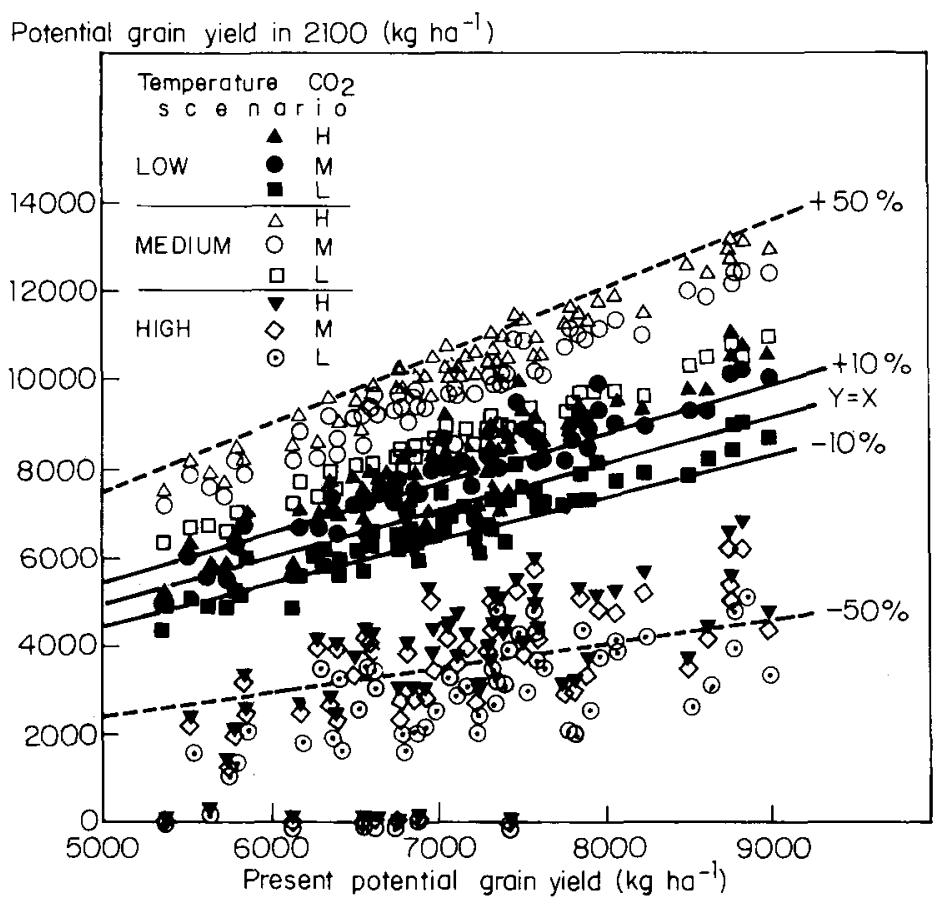

Fig. 5. Potential rice grain yields in the year 2100 versus present potential yields.

pending on $\mathrm{CO}_{2}$ scenario. For the middle temperature scenario a $5 \%$ decrease was calculated for the low $\mathrm{CO}_{2}$ scenario, and a 10-16\% increase for the middle and high $\mathrm{CO}_{2}$ scenario. Dramatic changes were found for the high temperature scenario: 50-60\% lower potential yield, with only limited effect of $\mathrm{CO}_{2}$ scenario. Unlike in the year 2020 , also differences became visible between the various regions, especially in the off season (Figures $6 f$ and $g$ ). Overall, the coefficients of variation changed considerably, although less for the tropical sites Pusakanegara and Muara, and for Khon Kaen, with stable but low potential yields.

\section{Effect of changing radiation on potential yield}

A $10 \%$ decrease in radiation intensity caused an overall reduction in potential yield of $7 \%$ (Table 3 ). Potential yield rose $6 \%$ when radiation increased $10 \%$. The changes in radiation hardly affected the relative differences in yield between the various scenarios for $\mathrm{CO}_{2}$ and temperature, and the effect on average potential yield was the same for main and off season. For the coming 30 years, changes in radiation level of this order of magnitude could affect potential yields more than changes in $\mathrm{CO}_{2}$ level. 
Table 3. Effect of changes in climate on average rice grain yields, calculated for potential situation and for nitrogen limited production, assuming no sink limitation. Average of all locations. Yields for the years 2020 and 2100 are relative to present yield $(\mathrm{t} \mathrm{ha}-1)$.

\begin{tabular}{|c|c|c|c|c|c|c|c|c|c|}
\hline \multirow[t]{3}{*}{ Temperature* } & \multirow[t]{3}{*}{$\mathrm{CO}_{2}{ }^{*}$} & \multicolumn{6}{|c|}{ Potential situation } & \multirow{2}{*}{\multicolumn{2}{|c|}{$\begin{array}{l}N \text { limited situation } \\
100 \% \text { radiation }\end{array}$}} \\
\hline & & \multicolumn{2}{|c|}{$100 \%$ radiation } & \multicolumn{2}{|c|}{$90 \%$ radiation } & \multicolumn{2}{|c|}{$110 \%$ radiation } & & \\
\hline & & $\begin{array}{l}\text { main } \\
\text { season }\end{array}$ & $\begin{array}{l}\text { off } \\
\text { season }\end{array}$ & $\begin{array}{l}\text { main } \\
\text { season }\end{array}$ & $\begin{array}{l}\text { off } \\
\text { season }\end{array}$ & $\begin{array}{l}\text { main } \\
\text { season }\end{array}$ & $\begin{array}{l}\text { off } \\
\text { season }\end{array}$ & $\begin{array}{l}\text { main } \\
\text { season }\end{array}$ & $\begin{array}{l}\text { off } \\
\text { season }\end{array}$ \\
\hline Present yield & & 7.252 & 7.352 & 7.252 & 7.352 & 7.252 & 7.352 & 2.225 & 2.080 \\
\hline \multicolumn{10}{|l|}{ Year 2020} \\
\hline \multirow[t]{3}{*}{$\mathrm{L}$} & $\mathbf{L}$ & 1.06 & 1.06 & 0.98 & 0.99 & 1.12 & 1.12 & 1.16 & 1.16 \\
\hline & $\mathbf{M}$ & 1.08 & 1.08 & 1.00 & 1.01 & 1.14 & 1.14 & 1.23 & 1.23 \\
\hline & $\mathrm{H}$ & 1.10 & 1.10 & 1.02 & 1.03 & 1.16 & 1.16 & 1.27 & 1.27 \\
\hline \multirow[t]{3}{*}{ M } & $\mathrm{L}$ & 0.98 & 0.99 & 0.91 & 0.92 & 1.04 & 1.04 & 1.01 & 0.99 \\
\hline & $\mathbf{M}$ & 1.00 & 1.01 & 0.93 & 0.94 & 1.06 & 1.07 & 1.07 & 1.05 \\
\hline & $\mathrm{H}$ & 1.02 & 1.03 & 0.95 & 0.96 & 1.07 & 1.08 & 1.11 & 1.09 \\
\hline \multirow[t]{3}{*}{$\mathbf{H}$} & L & 0.83 & 0.83 & 0.77 & 0.77 & 0.88 & 0.88 & 0.69 & 0.63 \\
\hline & $\mathbf{M}$ & 0.85 & 0.85 & 0.79 & 0.78 & 0.90 & 0.90 & 0.74 & 0.67 \\
\hline & $\mathrm{H}$ & 0.86 & 0.86 & 0.80 & 0.80 & 0.91 & 0.91 & 0.77 & 0.70 \\
\hline \multicolumn{10}{|l|}{ Year 2100} \\
\hline \multirow[t]{3}{*}{ L } & $\mathrm{L}$ & 1.21 & 1.21 & 1.12 & 1.12 & 1.27 & 1.27 & 1.32 & 1.32 \\
\hline & $\mathbf{M}$ & 1.38 & 1.39 & 1.29 & 1.30 & 1.46 & 1.47 & 1.71 & 1.75 \\
\hline & $\mathrm{H}$ & 1.45 & 1.46 & 1.35 & 1.36 & 1.54 & 1.55 & 1.87 & 1.89 \\
\hline \multirow[t]{3}{*}{ M } & $\mathrm{L}$ & 0.95 & 0.94 & 0.88 & 0.87 & 1.01 & 1.00 & 0.91 & 0.84 \\
\hline & $\mathbf{M}$ & 1.10 & 1.10 & 1.02 & 1.02 & 1.16 & 1.16 & 1.27 & 1.21 \\
\hline & $\mathrm{H}$ & 1.16 & 1.16 & 1.08 & 1.07 & 1.23 & 1.23 & 1.39 & 1.34 \\
\hline \multirow[t]{3}{*}{$\mathbf{H}$} & $\mathrm{L}$ & 0.42 & 0.33 & 0.38 & 0.29 & 0.45 & 0.36 & 0.20 & 0.14 \\
\hline & M & 0.52 & 0.42 & 0.47 & 0.37 & 0.56 & 0.46 & 0.31 & 0.21 \\
\hline & $\mathrm{H}$ & 0.56 & 0.46 & 0.51 & 0.41 & 0.60 & 0.50 & 0.35 & 0.24 \\
\hline
\end{tabular}

${ }^{*} \mathrm{H}=$ high, $\mathrm{M}=$ medium and $\mathrm{L}=$ low (see Table 2 ).

\section{Nitrogen limited production}

For the high temperature scenario, potential yields for the year 2020 were reduced by maximally $20 \%$ (Figure 4). Simulated nitrogen limited yields for the same temperature scenario were reduced by up to $50 \%$ (Figure 7). Compared to the potential yield, more variability in yield reduction was observed. For the middle and low temperature scenarios, the relative increase of yields under nitrogen limitation was somewhat higher than for potential situations. For the year 2100 the low tempera- 
Table 4. Effect of changes in climate on Coefficient of Variation (CV) of rice grain yields, calculated for potential situation and for nitrogen limited production, assuming no sink limitation. Average of all locations. CV for the years 2020 and 2100 is relative to present.

\begin{tabular}{|c|c|c|c|c|c|c|c|c|c|}
\hline \multirow[t]{3}{*}{ Temperature* } & \multirow[t]{3}{*}{$\mathrm{CO}_{2}^{*}$} & \multicolumn{6}{|c|}{ Potential situation } & \multirow{2}{*}{\multicolumn{2}{|c|}{$\begin{array}{l}\mathrm{N} \text { limited situation } \\
100 \% \text { radiation }\end{array}$}} \\
\hline & & \multicolumn{2}{|c|}{$100 \%$ radiation } & \multicolumn{2}{|c|}{$90 \%$ radiation } & \multicolumn{2}{|c|}{$110 \%$ radiation } & & \\
\hline & & $\begin{array}{l}\text { main } \\
\text { season }\end{array}$ & $\begin{array}{l}\text { off } \\
\text { season }\end{array}$ & $\begin{array}{l}\text { main } \\
\text { season }\end{array}$ & $\begin{array}{l}\text { off } \\
\text { season }\end{array}$ & $\begin{array}{l}\text { main } \\
\text { season }\end{array}$ & $\begin{array}{l}\text { off } \\
\text { season }\end{array}$ & $\begin{array}{l}\text { main } \\
\text { season }\end{array}$ & $\begin{array}{l}\text { off } \\
\text { season }\end{array}$ \\
\hline Present $\mathrm{CV}$ & & 0.05 & 0.07 & 0.05 & 0.07 & 0.05 & 0.07 & 0.09 & 0.10 \\
\hline \multicolumn{10}{|l|}{ Year 2020} \\
\hline \multirow[t]{3}{*}{$\mathbf{L}$} & $\mathbf{L}$ & 1.01 & 0.98 & 1.18 & 1.21 & 1.69 & 0.84 & 0.89 & 1.09 \\
\hline & $\mathrm{M}$ & 0.99 & 0.98 & 1.17 & 1.07 & 1.66 & 0.84 & 0.96 & 1.07 \\
\hline & $\mathbf{H}$ & 0.99 & 0.98 & 1.18 & 1.10 & 1.63 & 0.84 & 0.95 & 0.96 \\
\hline \multirow[t]{3}{*}{ M } & $\mathbf{L}$ & 1.33 & 1.14 & 1.13 & 1.32 & 1.56 & 0.99 & 1.12 & 1.14 \\
\hline & $\mathbf{M}$ & 1.29 & 1.14 & 1.22 & 1.32 & 1.92 & 0.97 & 1.16 & 1.10 \\
\hline & $\mathbf{H}$ & 1.27 & 1.15 & 1.21 & 1.32 & 1.88 & 0.98 & 1.14 & 1.10 \\
\hline \multirow[t]{3}{*}{$\mathrm{H}$} & $\mathbf{L}$ & 1.86 & 1.23 & 1.51 & 1.53 & 2.54 & 1.17 & 1.68 & 1.81 \\
\hline & $\mathbf{M}$ & 2.05 & 1.21 & 1.47 & 1.56 & 2.71 & 1.20 & 1.64 & 1.78 \\
\hline & $\mathbf{H}$ & 2.01 & 1.23 & 1.96 & 1.38 & 2.64 & 1.19 & 1.60 & 1.73 \\
\hline \multicolumn{10}{|l|}{ Year 2100} \\
\hline \multirow[t]{3}{*}{$\mathbf{L}$} & $\mathbf{L}$ & 1.33 & 1.00 & 1.18 & 1.18 & 1.19 & 0.98 & 0.89 & 0.93 \\
\hline & $\mathbf{M}$ & 1.05 & 1.06 & 1.31 & 1.07 & 1.69 & 0.96 & 0.80 & 0.89 \\
\hline & $\mathrm{H}$ & 1.06 & 1.06 & 1.37 & 1.10 & 1.60 & 0.97 & 0.72 & 0.87 \\
\hline \multirow[t]{3}{*}{$\mathbf{M}$} & $\mathbf{L}$ & 2.33 & 1.35 & 1.90 & 1.51 & 2.73 & 1.16 & 1.68 & 1.65 \\
\hline & $\mathbf{M}$ & 1.79 & 1.29 & 1.86 & 1.47 & 2.36 & 1.13 & 1.50 & 1.53 \\
\hline & $\mathbf{H}$ & 1.73 & 1.27 & 1.70 & 1.41 & 2.46 & 1.14 & 1.36 & 1.43 \\
\hline \multirow[t]{3}{*}{$\mathrm{H}$} & L & 9.43 & 3.14 & 9.34 & 3.31 & 10.24 & 2.86 & 3.43 & 2.74 \\
\hline & $\mathbf{M}$ & 8.34 & 2.74 & 8.07 & 2.93 & 8.40 & 2.71 & 3.36 & 2.53 \\
\hline & $\mathrm{H}$ & 7.77 & 2.75 & 7.45 & 2.97 & 8.20 & 2.62 & 3.31 & 2.52 \\
\hline
\end{tabular}

${ }^{*} \mathrm{H}=$ high, $\mathbf{M}=$ medium and $\mathrm{L}=$ low (see Table 2 ).

ture scenario resulted in yields that amount to more than $150 \%$ of the present values.

Water use efficiency

The combination of high $\mathrm{CO}_{2}$ and low temperature scenario resulted in an increasing water use efficiency. Figure 8 shows the calculated water use efficiency for Khon Kaen only, but the same trends were found for the other locations. The 'worst possi- 

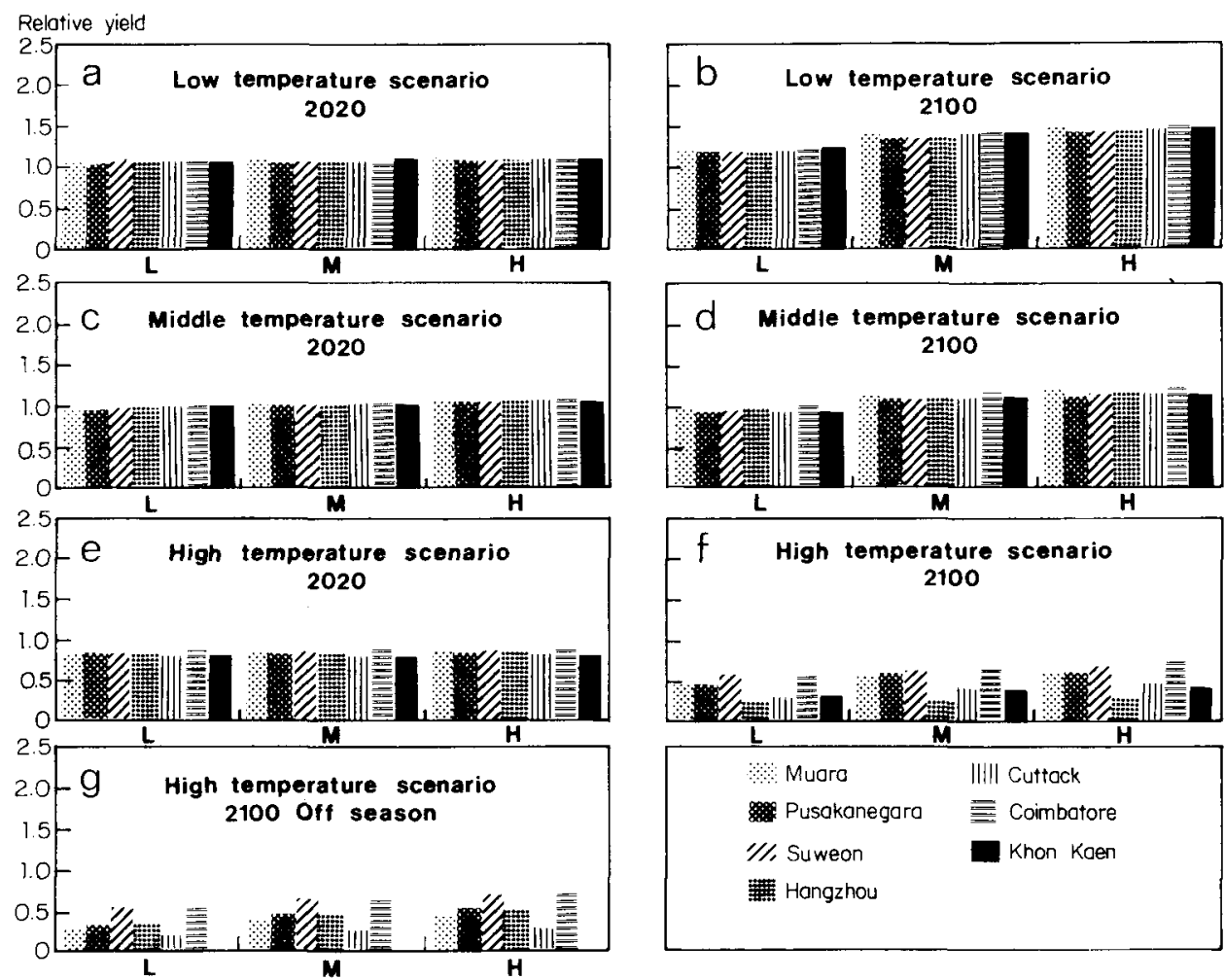

Fig. 6. Change in potential grain yield relative to present potential under various scenarios. a-f: main season; g: off season. Letters on the $x$-axis indicate the $\mathrm{CO}_{2}$ scenario: $\mathrm{L}=$ low; $\mathrm{M}=$ middle; $\mathrm{H}=$ high.

ble' conditions, a combination of low $\mathrm{CO}_{2}$ and high temperature scenario, reduced the water use efficiency, at least for the year 2020. Keeping the vapour pressure at the same level as at present implies dryer conditions with increasing temperature than when the percentage relative humidity in the air is kept the same. The effects of temperature and $\mathrm{CO}_{2}$ scenario on water use efficiency were more pronounced in the dryer conditions.

Changes in radiation intensity had little effect on the water use efficiency. A $10 \%$ decrease in radiation increased water use efficiency by $1.5 \%$, and an increase of $10 \%$ caused a $3 \%$ less efficient water use. This was consistent for all locations.

The combination of high temperature and low $\mathrm{CO}_{2}$ scenario resulted in a water use efficiency that was a little lower for nitrogen limited conditions compared to potential conditions. The reverse was true for scenarios that favour a high water use efficiency. Also under nitrogen limitation more water was needed than at present to produce the same amount of biomass in the high temperature scenario. 


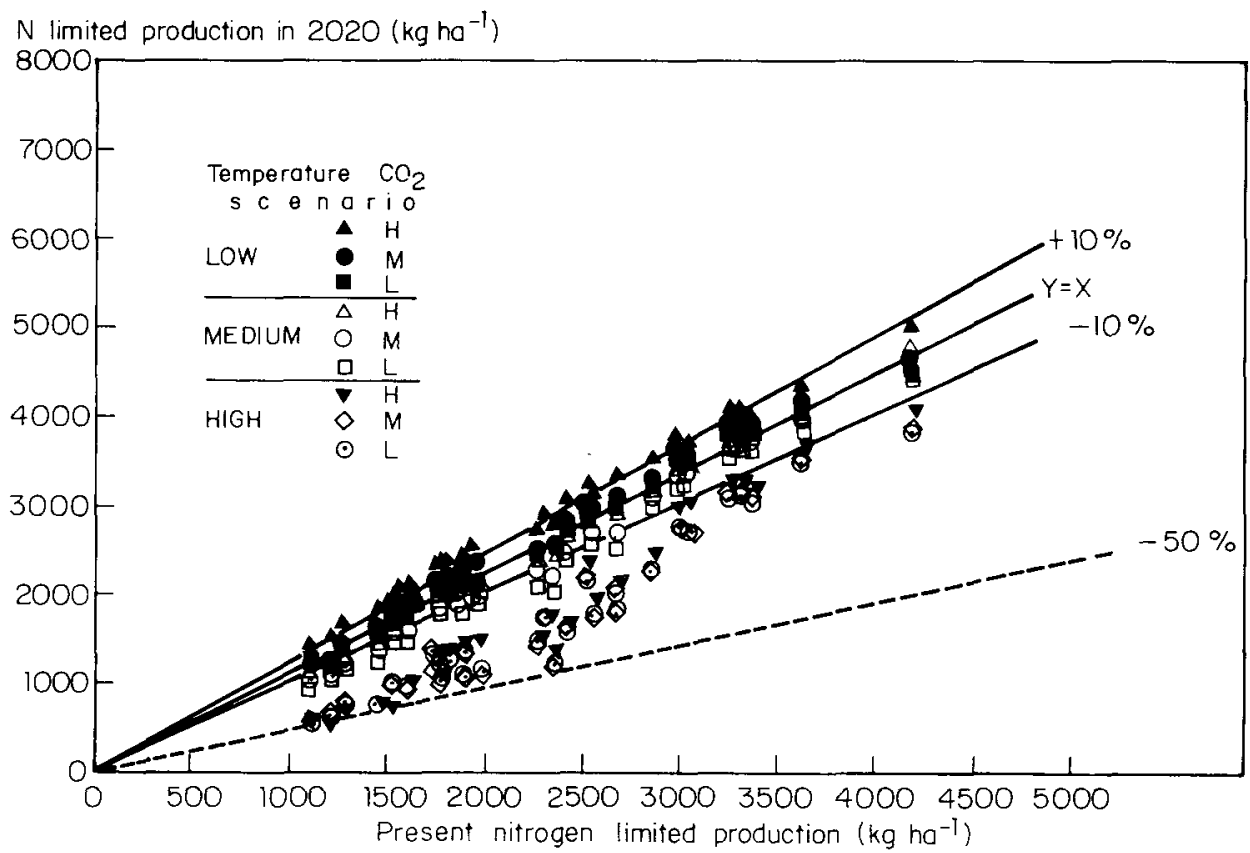

Fig. 7. Nitrogen limited production in the year 2020 in relation to present nitrogen limited production. Main season transplanting date, all sites.

\section{Discussion}

The crop parameters used in this study are for the current rice cultivar IR 36 . Present day rice cultivars show variation in tolerance to high temperature. Developments in the field of biotechnology might increase this plasticity. Conclusions on yield level or yield variability in this study not necessarily apply to the situation in the years 2020 of 2100 , when cultivars might be available that are different in physiological characteristics from those grown at present.

Furthermore, not all assumptions on crop characteristics and on changes in climate might be valid. The relations of PLMX and PLEA to $\mathrm{CO}_{2}$ (Figure 1) are simplified and only valid in the range of the experimental conditions $(250-2000 \mathrm{ppm}$ $\mathrm{CO}_{2}$ at $28-30{ }^{\circ} \mathrm{C}$ ). In the model the effect of temperature and of $\mathrm{CO}_{2}$ are multiplied to calculate PLMX and PLEA. Thus it is assumed that temperature affects the carboxylation resistance only (Goudriaan, pers. comm.). However, also the $\mathrm{CO}_{2}$ compensation point changes with temperature (Horie, 1979). PLMX and PLEA will therefore be reduced less at high temperature and high $\mathrm{CO}_{2}$ level than is assumed in the model. However, it is unknown how this is influenced by pretreatment temperature and $\mathrm{CO}_{2}$ level, or by nutrient availability. Lack of quantitative data for rice makes it difficult at present to model PLMX and PLEA with more accuracy. 


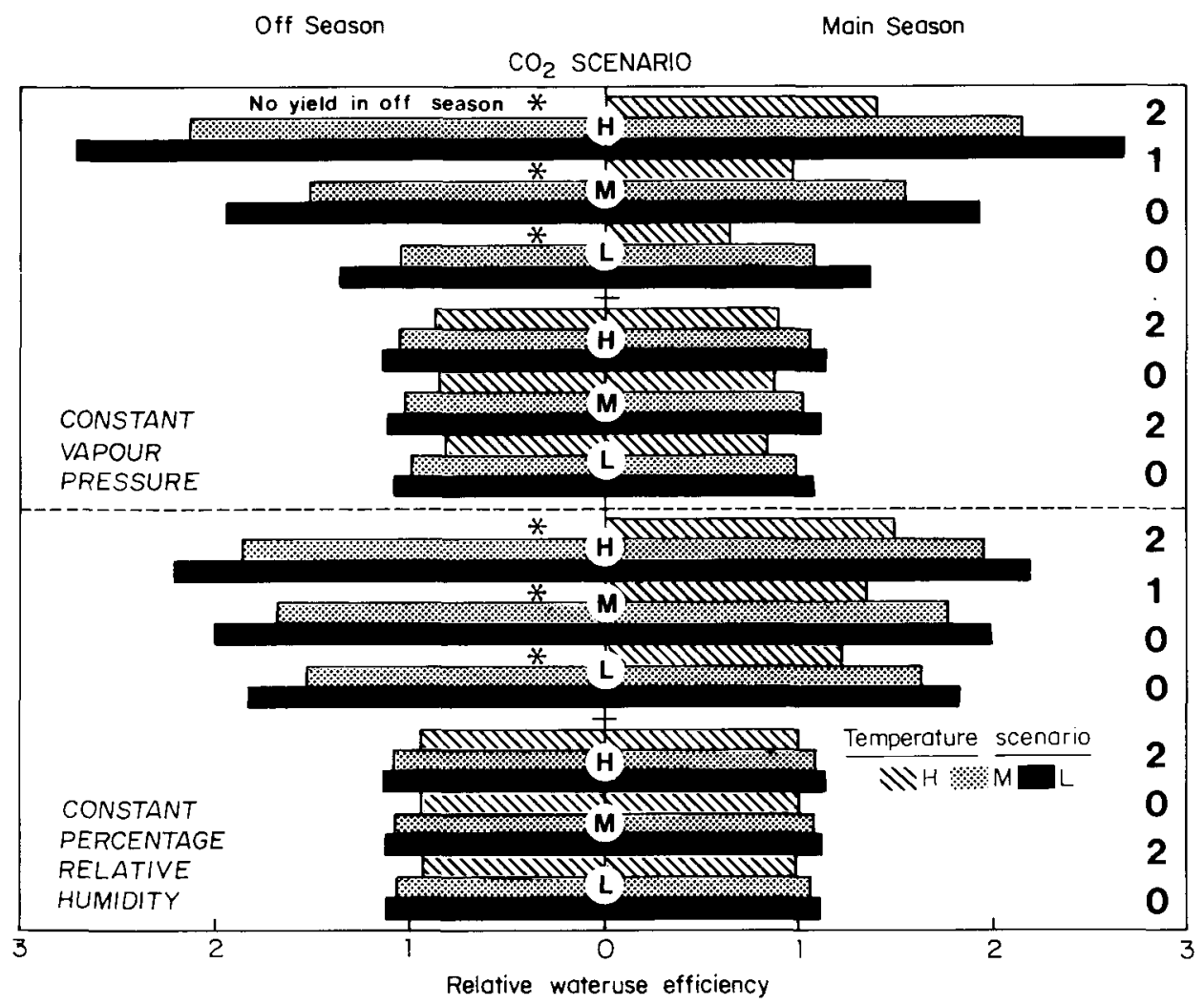

Fig. 8. Water use efficiency in Khon Kaen, as affected by temperature and $\mathrm{CO}_{2}$ scenarios, in the years 2020 and 2100 relative to present. Either the percentage relative humidity or the vapour pressure in 2020 and 2100 was kept the same as at present.

In the model it is assumed that leaf temperature equals air temperature. However, they can differ several degrees centigrade (Horie, 1979; Idso et al., 1981) especially when transpiration is hampered. High air temperature under water stressed conditions could result in a supra-optimal leaf temperature, with negative effects on photosynthesis. Phenological development of irrigated rice is strongly influenced by irrigation water temperature as long as the growing point is under water, or very close to the water level. Changes in air temperature might not result in the same changes in irrigation water temperature. High water or air temperature can reduce the number of grains and/or the grain filling, such that the yield is limited by the sink size (Yoshida, 1981). This is not taken into account by the model.

Increased $\mathrm{CO}_{2}$ level can speed up phenological development (Imai et al., 1985). The cause for this is unknown and the simulated rate of development is not affected by $\mathrm{CO}_{2}$ level.

When grown for a long period at higher temperature, rice plants have reduced amounts of nutrients in their tissue and lower specific leaf weight compared to 
plants grown at lower temperatures (Sato, 1970). Also their shoot/root ratio is lower (Imai et al., 1985; Shieh \& Liao, 1987). Maintenance respiration therefore could be lower, also because the relative effect of temperature on it might be different from that for crops raised at lower temperatures.

Effect of enhanced $\mathrm{CO}_{2}$ level on specific leaf weight is not clear (Imai et al., 1985; Goudriaan \& de Ruiter, 1983), and probably not as simple as is assumed in the model.

It is difficult to indicate how valid the calculated grain yields and water use efficiencies are in view of the assumptions on the physiological characteristics of the rice plant that were discussed before. Almost all equations and parameters that were used in the model to describe effects of higher temperatures and enhanced $\mathrm{CO}_{2}$ concentrations, were derived from experiments in which the plants were exposed to these conditions for only a part of their total growing period. There are some indications that the length of the pretreatment period has an effect on several of the physiological characteristics discussed before, but it is unclear to what extend the plants adapt to higher temperature and $\mathrm{CO}_{2}$ level when grown in those conditions for their whole growing period. Of the effects of temperature and $\mathrm{CO}_{2}$ increase on the plant characteristics or physiological processes that were not accounted for in het model, some might result in an increase in calculated grain yield, whereas others might reduce it. Effects on PLMX and PLEA, and on maintenance respiration probably fall in the first group, whereas effects on leaf temperature, on phenological development and on sink size might fall in the second group. With the simulation model used, in fact it is assumed that these positive and negative effects cancel out. This is a necessary simplification as long as no additional data are available on the effect of long-term effects of temperature and $\mathrm{CO}_{2}$ on the processes and characteristics discussed.

A $70 \%$ reduction of PLMX during the whole growing period to mimic $\mathrm{N}$ stress, resulted in various yield reductions. This is caused by different rates of photosynthesis, and by differences in accumulation of reserves contributing to grainfilling, in length of growing season, and in temperature and radiation level, between sites, transplanting dates and scenarios.

For wheat, a smaller effect of $\mathrm{CO}_{2}$ increase under low $\mathrm{N}$ availability was found (Goudriaan \& de Ruiter, 1983). Information on long-term effects of nitrogen level in the rice plant at various levels of temperature and $\mathrm{CO}_{2}$ concentrations in the air is needed to derive conclusions on validity of the model predictions.

In the high temperature scenario more water was needed to produce the same amount of rice as at present: water use efficiency decreased, and evaporation from soil and irrigation canals can be expected to increase. Even though water use efficiency of the crop increased in the low and middle temperature scenarios, it is not clear whether this will result in lower water requirements to grow the crop. A possible higher total transpiration could result from a higher biomass production. Together with a higher evaporation from soil and irrigation canals, this might result in a higher demand for water.

Only a limited set of weather data was available per location. It is not clear to what extent these data cover the real variation. Especially when only three years 
were available, chances are that only relative cool or relative warm years were used. Any bias in the weather data used will be enlarged in the estimations of weather for the year 2020, and even more so for the year 2100. It is assumed however, that the simulated trends of the effects of climate change are valid even when a biassed set of weather data was used.

\section{Conclusions}

Potential and nitrogen limited yields of present day cultivars in the year 2020 can be expected to increase in the low temperature change scenario whereas they will decrease in the high temperature change scenario, irrespective of $\mathrm{CO}_{2}$ scenario. Assuming that nitrogen limitation only affects the photosynthetic rate, the model predicts nitrogen limited yields to respond relatively more than the potential yields. It is unclear however, whether this conclusion also holds when the effect is simulated of $\mathrm{CO}_{2}$ and temperature increase and of $\mathrm{N}$ limitation on other yield determining processes (e.g. respiration, sink formation).

Only after the year 2020, and only in the high temperature scenario, regional differences can be expected in relative changes in potential and nitrogen limited yields. Locations affected most are those between 10 and $35^{\circ} \mathrm{N}$ (Khon Kaen, Cuttack and Hangzhou). Changes in radiation intensity, if in the order of $10 \%$ of current values, can affect potential production in the year 2020 more than the expected changes in $\mathrm{CO}_{2}$ concentration.

Water use efficiency will decrease in the year 2020 as compared to present values in the high temperature change scenario. In studies on irrigation requirements this should be taken into account. To select cultivars suited for possible future weather conditions, more knowledge is needed about the long-term effects of high temperature and high $\mathrm{CO}_{2}$ level on their rates of photosynthesis and dry matter production.

\section{Acknowledgements}

Many thanks are due to the institutes that provided the weather data:

- P.R. China: the Chinese National Rice Research Institute and the Zhejiang Agricultural University, both in Hangzhou;

- India: the Central Rice Research Institute (Cuttack), the Tamil Nadu Agricultural University (Coimbatore), and the Multiple Cropping Department of IRRI (Los Banos, Philippines);

- Indonesia: the Bogor Research Institute for Food crops and the Sukamandi Research Institute for Food crops;

- Thailand: the Rice Farming Systems Project of the Khon Kaen University;

- Korea: the Agricultural Sciences Institute and the Crop Experiment Station, both in Suweon.

Dr F. W. T. Penning de Vries, Dr J. Goudriaan, and D. van Kraalingen are gratefully acknowledged for commenting the manuscript. Many thanks also to Mrs R. Badrina, for doing an excellent job drawing the figures. 


\section{References}

Akita, S., 1980. Studies on the differences in photosynthesis and photorespiration among crops. II. The differential responses of photosynthesis, photorespiration and dry matter production to carbon dioxide concentration among species. Bulletin of the National Institute of Agricultural Sciences (Series D) 31: 59-94.

Clark, W. C., K. H. Cook, G. Marland, A. M. Weinberg, R. M. Rotty, P. R. Bell, L. J. Allison \& C. L. Cooper, 1982. The Carbon Dioxide question: perspectives for 1982. In: W. C. Clark (Ed.), Carbon Dioxide Review: 1982, p. 3-44. Clarendon Press, Oxford.

Cooper, C. F., 1982. Food and fiber in a world of increasing Carbon Dioxide. In: W. C. Clark (Ed.), Carbon Dioxide Review: 1982, p. 299-320. Clarendon Press, Oxford.

Curry, R. B., R. M. Peart, J. W. Jones, K. J. Boote \& L. H. Allen, 1988. Simulation as tool for analyzing crop response to climate change. Paper 88-7512, ASEA International Winter Meeting, 1988.

Diepen, C. A. van, H. van Keulen, F. W. T. Penning de Vries, I. G. A. M. Noy \& J. Goudriaan, 1987. Simulated variability of wheat and rice yields in current weather conditions and in future weather when ambient $\mathrm{CO}_{2}$ has doubled. Simulation Report CABO-TT Nr 14, CABO, Wageningen, Netherlands, $40 \mathrm{pp}$.

Dingkuhn, M., 1985. Physiologische Faktoren der Trockenheitsresistenz bei Reis. Ph. D. Thesis, University of Hamburg, West Germany, $219 \mathrm{pp}$.

Fukai, S., E. Kuroda \& T. Yamagishi, 1985. Leaf gas exchange of upland and lowland rice varieties. Photosynthesis Research 7:127-135.

Fukui, H., 1982. Variability of rice production in tropical Asia. In: Drought resistance in crops with emphasis on rice, p. 17-37. IRRI, Los Banos, Philippines.

Gammon, R. H., E. T. Sundquist \& P. J. Fraser, 1985. History of Carbon Dioxide in the atmosphere. In: J. R. Trabalka (Ed.), Atmospheric Carbon Dioxide and the global Carbon cycle, p. 25-62. US Dept of Energy, DOE/ER-0239.

Goudriaan, J., 1986. A simple and fast numerical method for the computation of daily totals of crop photosynthesis. Agricultural and Forest Meteorology 38: 249-254.

Goudriaan, J. \& R. J. Bijlsma, 1987. Effect of $\mathrm{CO}_{2}$ enrichment on growth of faba beans at two levels of water supply. Netherlands Journal of Agricultural Science 35: 189-191.

Goudriaan, J. \& H. E. de Ruiter, 1983. Plant growth in response to $\mathrm{CO}_{2}$ enrichment, at two levels of nitrogen and phosphorus supply. 1. Dry matter, leaf area and development. Netherlands Journal of Agricultural Science 31: 157-169.

Goudriaan, J., H. H. van Laar, H, van Keulen \& W. Louwerse, 1984. Simulation of the effect of increased $\mathrm{CO}_{2}$ on assimilation and transpiration of a closed crop canopy. Wissenschaftliche Zeitschrift Humboldt Universitaet zu Berlin, Math.-Nat. R. 33:352-356.

Goudriaan, J., H. H. van Laar, H. van Keulen \& W. Louwerse, 1985. Photosynthesis, $\mathrm{CO}_{2}$ and plant production. In: W. Day \& R. K. Atkin (Eds), Wheat growth and modelling, p. 107-121. NATO ASI Series A: Life Sciences 86. Plenum Press.

Herrera-Reyes, C. \& F. W. T. Penning de Vries, 1990. Evaluation of a model for simulating the potential production of rice crops. Philippine Crop Science Journal (in press).

Heu, H., 1978. Studies on physiological and ecological characteristics of indica $\mathrm{x}$ japonica rice varieties - emphasizing temperature response. Research Report Office of Rural Development, Korea 20:1-48.

Horie, T., 1979. Studies on photosynthesis and primary production of rice plants in relation to meteorological environments. II. Gaseous diffusive resistances, photosynthesis and transpiration in the leaves as influenced by atmospheric humidity, and air and soil temperatures. Journal of Agricultural Meteorology 35:1-12.

Huke, R. E., 1982. Rice area by type of culture: South, SouthEast and East Asia. IRRI, Los Banos, Philippines, 32 pp.

Idso, S. B., R. J. Reginato, R. D. Jackson \& P. J. Pinter, 1981. Foliage and air temperatures: evidence for a dynamic 'equilibrium point'. Agricultural Meteorology 24: 223-226.

Imai, K., D. F. Coleman \& T. Yanagisawa, 1985. Increase in atmospheric partial pressure of Carbon Dioxide and growth and yield of rice (Oryza sativa L.). Japanese Journal of Crop Science 54: 413-418. 
IRRI, 1988. World rice statistics 1987. IRRI, Los Banos, Philippines, $257 \mathrm{pp}$.

Ishii, R., R. Phsugi \& Y. Murata, 1977. The effect of temperature on the rates of photosynthesis, respiration and the activity of RuDP Carboxylase in barley, rice and maize leaves. Japanese Journal of Crop Science 46: 516-523.

Jaeger, J., 1988. Developing policies for responding to climatic change. WMO/TD-no 225, $53 \mathrm{pp}$.

Jones, P., L. H. Allen, J. W. Jones \& R. Valle, 1984. Photosynthesis and transpiration responses of soybean canopies to short- and longterm $\mathrm{CO}_{2}$ treatments. Agronomy Journal 77: 119-126.

McDonald, D. J., 1971. The effect of temperature and light on the rate of photosynthesis of 20 rice varieties and hybrids. Ph.D. thesis, Texas A \& M, 129 pp.

Oldeman, L. R. \& M. Frère, 1982. A study of the agroclimatology of the humid tropics in Southeast Asia. Technical Report FAO/UNESCO/WMO. FAO, Rome, $229 \mathrm{pp}$.

Oldeman, L. R., D. V. Seshu \& F. B. Cady, 1987. Response of rice to weather variables. In: Weather and rice, p. 5-39. IRRI, Los Banos, Philippines.

Osada, A., 1964. Studies on the photosynthesis of indica rice. Proceedings of the Crop Science Society of Japan 33: 69-76.

Penning de Vries, F. W. T., D. M. Jansen, H. F. M. ten Berge \& A. H. Bakema, 1989. Simulation of ecophysiological processes of growth of several annual crops. Pudoc, Wageningen, $271 \mathrm{pp}$.

Saltoh K. \& K. Ishihara, 1987. Effect of vapour pressure deficit on photosynthesis of rice leaves with reference to light and $\mathrm{CO}_{2}$ utilization efficiency. Japanese Journal of Crop Science 56: 163-170.

Sato, K., 1970. Effects of environmental conditions of long and short duration on subsequent leaf $\mathrm{CO}_{2}$ assimilation rates of rice plant under a definite standard condition. Proceedings of the Crop Science Society of Japan 39: 370-375.

Shieh Y. J. \& W. Y. Liao, 1987. Influence of growth temperature and nitrogen nutrition on photosynthesis and nitrogen metabolism in the rice plant (Oryza sativa L.). Botanical Bulletin of the Academica Sinica 28: 151-167.

Tanner, C. B. \& T. R. Sinclair, 1983. Efficient use of water in crop production: research or re-search. In: H. M. Taylor, W. R. Jordan \& T. R. Sinclair (Eds), Limitations to efficient water use in crop production, p. 2-17. NASA-CSSA-SSSA, Madison, USA.

Trabalka, J. R., J. A. Edmonds, J. Reilly, R. H. Gardner \& L. D. Voorhees, 1985. Human alterations of the global carbon cycle and the projected future. In: J. R. Trabalka (Ed.), Atmospheric Carbon Dioxide and the global Carbon cycle, p. 248-287. US Dept of Energy. DOE/ER-0239.

Vong, N. Q. \& Y. Murata, 1977. Studies on the physiological characteristics of $C_{3}$ and $C_{4}$ species. I. The effects of air temperature on the apparent photosynthesis, dark respiration, and nutrient absorption of some crops. Japanese Journal of Crop Science 46: 45-52.

Yoshida, S., 1981. Fundamentals of rice crop science. IRRI, Los Banos, Philippines, 269 pp.

Yoshida, S., 1983. Rice. In: Potential productivity of field crops under different environments, p. 103127. IRRI, Los Banos, Philippines.

Wit, C. T. de, 1958. Transpiration and crop yields. Agricultural Research Reports 64.6. Pudoc, Wageningen, $88 \mathrm{pp}$.

Wit, C. T. de \& F. W. T. Penning de Vries, 1982. La synthèse et la simulation des systèmes de production primaire. In: F. W. T. Penning de Vries \& M. A. Djitèye (Eds), La productivité des pâturages sahelien, p. 23-25. Agricultural Research Reports 918. Pudoc, Wageningen. 